\title{
Determinants of Self-Reported Illness: An Experience from Social Health Insurance Program in Nepal
}

\author{
Deepak Raj Paudel \\ School of Business, Pokhara University, Kaski, Nepal. \\ Kathmandu University School of Education, Lalitpur, Nepal \\ Email: deepakpaudel1974@gmail.com
}

\begin{abstract}
Even though the ultimate goal of social health insurance program is to increase the utilization of health services and reduce the health care expenditure, individuals in developing countries generally do not visit a healthcare provider or spend on healthcare unless they perceive themselves as ill. Thus, the determinants of such illness reporting could have practical significance in a setting, where the social health insurance program was first being implemented in Nepal.

Philosophically, this study follows a post-positivism or empiricism research paradigm. The ontological assumption of this study is a singular reality and regarding the epistemological assumption, this study considers an objective reality, a deductive method of quantitative inquiry. A cross-sectional survey was performed among 6480 individuals from 1048 households located in 26 wards of Kailali district after twenty-one months of the implementation of health insurance program in Nepal. The sample was selected in two stages, first being the selection of wards and second being the households. Data analyses were mainly based on chi-square test and logistic regression analysis.
\end{abstract}

1 Paudel 
The study revealed that out of total 6480 surveyed individuals, 1590 (24.5\%) individuals reported illness and the most commonly self-reported illness was cold/cough/fever in the month prior to the survey. The logistic regression analysis revealed that a number of socioeconomic factors such as health insurance coverage, gender, education level, economic status and employment status are significant predictors of illness reporting. Being insured, household members were more likely to report illness compared to their counterparts (Odds ratio $=1.40$, 95\% Confidence Interval=1.24-1.59). Females were more likely to report illness compared to males. Members with secondary level of education were significantly less likely to have illnesses than the members with no formal education. Household members from higher household economic status and employed were significantly less likely to have an illness.

The findings from this study could inform policy in the ongoing national health insurance debate in Nepal and elsewhere. Since individuals having health insurance are more likely to report illness compared to uninsured, there is need to expand the health insurance program thought the country. Despite some methodological constraints, this study delivers new information on the occurrences of self-reported illnesses among the Nepalese population. This can help policy makers to formulate proper interventions to protect the poor from the financial burden associated with poor-health.

Keywords: Illness reporting, Health insurance, Poverty

\section{INTRODUCTION}

Illness is a health shock but it is perceived differently by individuals according to their various socioeconomic status. Ill health could reduce household investment in human capital, physical capital, and other consumptions that are critical to human well-being (Wang et al., 2006). Even small costs for common illnesses can be financially disastrous for poor households with no insurance coverage (Xu et al., 2003).

Poverty and ill-health are often correlated, creating a vicious circle (Wagstaff, 2002). Ill-health often intensifies poverty, especially in the absence of effective social health protection and poor people tend to have worse health than the better-off do (Gwatkin et al., 2007). Despite considerable improvements in the health sector, access to affordable and effective health care remains a problem in Nepal. For example, household health care expenditure in Nepal constitutes a large share $(55.4 \%)$ of the total current health expenditure (Ministry of Health and

Nepalese Journal of Insurance and Social Security 2 
Population [MOHP], 2018). This indicates that financial burden on households due to health care is high in Nepal. Considerable progress in measuring the impact of ill-health on household welfare has been made in Nepal, such as expansion of health insurance coverage in the recent years. However, there are still knowledge gaps. Despite these initiatives, the country still faces significant challenges in scaling up health insurance schemes to ensure access to health services, especially for the poor, and prevent financial burden associated with illness-related healthcare costs. To develop appropriate policies to protect households against impoverishing effects of illhealth, there is a need of an understanding of the multiple and a complex pathway for the wellbeing of persons of poor health.

Though the ultimate aim of social health insurance program is to increase the utilization of health services and reduce the health care expenditure, individuals in developing countries generally do not visit a healthcare provider or spend on healthcare unless they perceive themselves as ill. Thus, it is difficult to assess the utilization of health services and to estimate health care expenditure for several reasons. First, individuals in developing countries generally do not visit a healthcare provider or spend much on healthcare unless they perceive themselves as either ill or injured (Rous \& Hotchkiss, 2003). Second, expenditure is likely to be a function of the type of provider visited (Rous \& Hotchkiss, 2003). Since the type of provider visited and expenditure are conditional upon the individual's illness reporting, this study tries to estimate the level of such illness reporting and its possible determinants.

In order to address the financial constraint in health services due to ill-health, the Government of Nepal has implemented the Social Health Insurance Program (SHIP) in 2016. However, the program has been facing many challenges and only small segments of the population are enrolled under Social Health Insurance (SHI) scheme (Pokharel \& Silwal, 2018; World Bank, 2017). Despite the fact that the research pertaining to illness reporting, out of pocket health expenditure and utilization is sporadically observed in the past, limited research papers have been published with respect to SHI scheme, particularly, in Nepalese context. Moreover, there are substantial evidences that ill-health is a key cause of poverty especially in developing countries (Ir et al., 2010). However, available methods for measuring the impact of ill-health on household welfare display several shortcomings and new studies are thus needed (Ir et al., 2010; Ross \& Vaughan, 1986). In the light of above discussion, in order to understand the prevalence of illness and its 
potential determinants, this study was conducted in Kailali, where social health insurance program was first time implemented in Nepal, as a part of doctoral research project.

\section{METHODS}

\subsection{A Brief Introduction of Social Health Insurance Program of Nepal}

The Social Health Insurance Program (SHIP) is a social protection program of Government of Nepal, which aims to enable its citizens to access health care services without having a financial burden. The program expects to prevent people from falling into poverty due to health care costs. The SHIP is a family-based health insurance scheme initiated by the Social Health Security Development Committee (SHSDC). The program was first implemented in Kailali district of Nepal and it is currently at the stage of expansion.

\subsection{Study Design and Setting}

A cross-sectional household survey was conducted between November 2017 and January 2018 in Kailali district after 21 months of the implementation of SHIP in Nepal. Kailali is the district where SHIP was first implemented in Nepal. In Kailali, there are approximately 142 thousand households with an average family size of 5.44 (Central Bureau of Statistics [CBS], 2012). The district has significantly higher poverty level as compared to national average (34\% versus $24 \%$ ) (CBS/The World Bank, 2013).

\subsection{Sample Size, Cluster Size and Number of Clusters}

The sample size was calculated using United Nations (2008) applying multistage cluster sampling. Assuming 50\% of proportion of success of a key indicator, 95\% desired level of confidence, $5 \%$ margin of error, 3 as design effect, and $7.5 \%$ as non-response rate, the sample size was 1066 households. Normally, 50\% is an optimum value for proportion of key success indicator. The value of design effect usually ranges from 1.5 to 4.5 (Shackman, 2001), so, an average value was assumed. Non-response rate of $5 \%$ to $10 \%$ is most common for household surveys especially in developing countries (United Nations, 2008). Thus, an average value of 5\% and $10 \%$ was assumed.

The value of the design effect depends on cluster size and intra-class correlation coefficient(Ross, 2005). Assuming design effect as 3 and intra-class correlation coefficient as 0.05 , the cluster size was 41 . In practice, the value of intra-class correlation coefficient ranges from 0.05 to 0.50 (Ross, 2005). A higher value indicates more similarity within the individuals'

Nepalese Journal of Insurance and Social Security 4 
characteristic whereas smaller value indicates less similarity. Thus, less similarity has been assumed. Finally, using sample size as 1066 and dividing it by cluster size of 41, the number of clusters or wards was 26 . However, only 1048 households were surveyed in this study, with a non-response rate of $1.7 \%$.

\subsection{Sampling Procedure}

A two-stage cluster sampling design was employed. At the first stage, 26 wards comprising at least ten insured households from a total of 126 wards were randomly selected. The rationale behind selecting only wards comprising at least ten insured households was similar to the 2017 World Bank study regarding Nepal's SHIP (World Bank, 2017). Further, since Kailali had less than $5 \%$ of insurance enrollment, and as the main objective of the study was to find the effect of SHIP on health care expenditure, so wards with relatively higher number of enrollments were selected. At the second stage, 41 households were randomly sampled from each ward. In each ward, about $25 \%$ of the insured households were selected such that comparison in health expenditure was meaningful. In other words, the case-control ratio was approximately $1: 3$ and the design protocol was approved by Kathmandu University (KU). The information regarding ward level insurance enrollment was obtained from the local office, Social Health Security Development Committee (SHSDC), Kailali district. The households from each ward were selected across the radius of ward office as per the latest census of Nepal.

\subsection{Questionnaire Design and Data Collection Procedures}

An initial version of a structured survey questionnaire was developed based on an intensive review of previous related studies and similar surveys conducted in Nepal. The final version of the instrument was prepared after incorporation of comments and feedbacks from subject experts, field testing to the potential respondents, presenting the questionnaire to a group of experts and Ph.D. thesis supervisors, receiving suggestions from concerned ethical bodies and pilot testing the draft versions. Adopting these procedures, the instrument ensured reliability and all types of validity as well as contextualized it in Nepalese context.

The study considered the household head or the most knowledgeable adult in a selected household an eligible respondent. Seven enumerators were assigned in the fixed number wards. Supervision was insured by the principal investigator. Enumerators were given intensive training and they also had experiences of collecting the data of large-scale surveys. A simulation exercise 
among the enumerators was conducted in order to minimize the plausible error. The respondents were informed about the purpose of the study and were assured about the confidentiality of their responses.

\subsection{Variables}

The dependent variable in this study is the illness reporting. The independent variables include different factors such as household and community as suggested by earlier research (Beogo et al., 2016; Masiye \& Kaonga, 2016; Wang et al., 2012). Household economic status was constructed by summing all food as well as non-food expenditures and consumer durable items (Deaton $\&$ Zaidi, 2002).

\subsection{Data Analysis}

First, background characteristics of study participants and the percentage of self-reported illness have been presented by means of descriptive statistics. Second, bivariate analysis has been carried out between each of socio-demographic factors and illness reporting using chi-square test. Finally, logistic regression analysis was employed to find the determinants of illness reporting. Before logistic regression was applied, the multicollinearity among the independent variables was assessed and none were highly correlated. The fitted model displays the estimated adjusted odds ratios (AORs) along with 95\% confidence interval (CI). Survey data was entered into Census and Survey Processing System (CSPro) version 7.0 software. Statistical analysis was performed with STATA 12.0 (StataCorp, 2012).

\subsection{Ethical Approvals}

The study was supported by the University Grants Commission of Nepal under Ph.D. Fellowship. Ethical clearance was obtained from the Nepal Health Research Council (the protocol registration number 398/2017) and Pokhara University Research Center, Nepal. The data collection approval was received from SHSDC, Nepal. The study was approved by Kathmandu University School of Education (KUSOED) as a part of Ph.D. research project.

\section{RESULTS}

\subsection{Illness Reporting, Disease Types and Perceived Severity of Illness}

Illness reporting was analyzed among the usual members in the household. Out of total 6480 surveyed household members, nearly one in four members $(24.5 \%)$ reported that they were ill in the month prior to the survey (Table 1). If an illness was reported during the month prior to the 
survey, the members were asked about the type of most recent reported illness and its severity. Each reported illness that had been diagnosed by an allopathic or ayurvedic doctor and the symptoms of an undiagnosed illness were coded according to a disease list that we based on the results of a previous study conducted in Nepal (Saito et al., 2014).

The most commonly self-reported illness in the month prior to the survey was cold/cough/fever followed by gastritis/abdominal pain. This result is consistent with the latest national survey, which found that cold/cough/fever was the most prevalent illness throughout the year in Nepal (CBS, 2011). Besides, the 2014 district health insurance assessment report also revealed the similar findings suggesting that cold and fever were the most commonly reported illness

Table 1. Illness Reporting, Disease Types and Perceived Severity of Most Recent Illness

\begin{tabular}{lll}
\hline Characteristics & Number & Percent \\
\hline Illness reporting (n=6480 individuals) & & \\
Yes & 1590 & 24.5 \\
No & 4890 & 75.5 \\
Self-reported diseases/symptoms type of most recent illness(n=1590) & & \\
Cold/Cough/Fever & 474 & 29.8 \\
Gastritis/Abdominal pain & 166 & 10.4 \\
Arthritis/Appendicitis & 136 & 8.6 \\
Respiratory/Asthma & 110 & 6.9 \\
Skin disease & 102 & 6.4 \\
Headache/Migraine & 74 & 4.7 \\
Eye/Nose/Teeth (ENT) & 71 & 4.5 \\
Muscle/Bone/Paralysis & 70 & 4.4 \\
Anemia & 55 & 3.5 \\
Pressure & 54 & 3.4 \\
Stone/Hernia & 45 & 2.8 \\
Gynecological/Pregnancy & 44 & 2.8 \\
Diarrhoea & 43 & 2.7 \\
Heart disease & 38 & 2.4 \\
Injury & 37 & 2.3 \\
Diabetes & 32 & 2.0 \\
Other health problems & 39 & 2.5 \\
High severe & & \\
Severe & 174 & 10.9 \\
Little severe & 493 & 31.0 \\
Not severe & 680 & 42.8 \\
& 243 & 15.3 \\
\hline
\end{tabular}

7 Paudel 
Volume $3 \quad$ Issue $3 \quad$ Dec 2020

(KOICA-Nepal Health Insurance Support Project [NHISP], 2014). Diseases such as arthritis, respiratory problems were also most common in the study area. More than two-fifths (42\%) of illnesses were perceived as severity or high severity category.

\subsection{Illness Reporting by Individual Characteristics}

Out of 6480 surveyed individuals, 1590 (24.5\%) reported illness in the month prior to the survey. Table 2 shows that large disparities are apparent across the subgroups of household members, being ill in the month prior to the survey. Females were more likely to report illnesses and injuries compared to males, and the differences are significant using chi-square test $(\mathrm{p}<0.01)$. Being household heads, respondents were no more statistically likely to report an illness.

The variable age showed a significant variation in the reported illness $(\mathrm{p}<0.01)$. For example, the proportion of reported illness was higher among individuals aged 60 or more and children under 5 years $(44 \%, 40 \%)$ as compared to the individuals 5 to 59 years $(21 \%)$. Individuals' education level showed large differentials in the reported illness with the highest among pre-schooling children (37\%). The proportion of respondents being ill fell from $31 \%$ among those with no education to $18 \%$ among those with tertiary level of education $(\mathrm{p}<0.01)$.

With regard to marital status, the divorcee /separated individuals are more likely to report the illness as compared to the unmarried or currently married individuals and the differences are statistically significant using chi-square test at $1 \%$ level of significance. People not engaged in work were more likely to report illness than people with occupations. Students were less likely to report illness as compared to other occupational groupings. For example, only $18 \%$ of students reported that they were ill in the month prior to survey, whereas $26 \%$ of the individuals were sick among those who worked in the formal sector, and the relationship is statistically significant between occupation status and being sick during the past month at less than $1 \%$ level of significance as per the chi-square test.

Table 2. Illness Reporting by Individual Characteristics in the Month Prior to the Survey

\begin{tabular}{lll}
\hline Characteristics & $\begin{array}{l}\text { Number of cases } \\
\text { in each category }\end{array}$ & $\begin{array}{l}\text { Percent } \\
\text { of illness }\end{array}$ \\
\hline Gender*** & & \\
Male & 3207 & 21.7 \\
$\quad$ Female & 3273 & 27.3 \\
Being head or not head & &
\end{tabular}

Nepalese Journal of Insurance and Social Security $~ 8$ 
Vol. 3(3) Dec 2022 ISSN: 2565-4942 (Print) 2738-9693 (online)

\begin{tabular}{lll}
\hline Characteristics & $\begin{array}{l}\text { Number of cases } \\
\text { in each category }\end{array}$ & $\begin{array}{l}\text { Percent } \\
\text { of illness }\end{array}$ \\
\hline Head & 1048 & 25.9 \\
$\quad$ Not head & 5432 & 24.3 \\
Age group in years*** & & \\
$\quad$ Less than 5 (Child) & 446 & 39.9 \\
$\quad$ 5 to 59 (Neither child nor senior) & 5507 & 21.4 \\
$\quad$ 60 or more (Senior) & 527 & 44.1 \\
Education level *** a & & \\
$\quad$ No formal education & 1892 & 31.1 \\
$\quad$ Early childhood development & 336 & 37.2 \\
$\quad$ Primary & 1270 & 21.7 \\
$\quad$ Secondary & 2076 & 20.9 \\
$\quad$ Tertiary & 906 & 18.4 \\
Marital status***b & & \\
$\quad$ Unmarried & 2914 & 21.7 \\
$\quad$ Married & 3347 & 25.8 \\
$\quad$ Divorced/Separated & 219 & 42.9 \\
Occupation status*** c & & \\
$\quad$ Not working & 1952 & 31.0 \\
$\quad$ Working in informal sector & 2235 & 22.8 \\
$\quad$ Student & 1465 & 18.1 \\
$\quad$ Working in formal sector & 828 & 25.5 \\
\hline Total of each variable & 6480 & 24.5 \\
\hline
\end{tabular}

$*^{* *} p<0.01 . \quad * * p<0.05 . \quad * p<0.10 . p$-value is based on Pearson's $\chi^{2}$ statistic. $a=$ Head's education if aged $<3$ years. $b=$ Unmarried if $<10$ years. $c=$ Head's occupation if aged $<10$ years.

\subsection{Illness Reporting by Household Characteristics}

Table 3 presents the illness reporting of household population according to their household characteristics. Individuals in households headed by females were statistically more likely to report illness than individuals in households headed by males (28\% vs. 24\%). The age of head did not show any significant association with the illness reporting of individual household member. Education level of household head showed a significant positive association with reporting illness in the month prior to the survey. The proportion of individuals reporting illness rose from $21 \%$ among those whose head had no education to $31 \%$ among those whose head had tertiary level education $(\mathrm{p}<0.01)$.

Table 3. Illness Reporting by Household Characteristics in the Month Prior to the Survey

9 Paudel 
Volume 3 Issue $3 \quad$ Dec 2020

\begin{tabular}{|c|c|c|}
\hline Characteristics & $\begin{array}{l}\text { Number of cases } \\
\text { in each category }\end{array}$ & $\begin{array}{l}\text { Percent } \\
\text { of illness }\end{array}$ \\
\hline \multicolumn{3}{|l|}{ Head's gender $* *$} \\
\hline Male & 5838 & 24.2 \\
\hline Female & 642 & 27.7 \\
\hline \multicolumn{3}{|l|}{ Head's age in years } \\
\hline Less than 60 (Economically active) & 5407 & 24.3 \\
\hline 60 or more (Senior citizen) & 1073 & 26.0 \\
\hline \multicolumn{3}{|l|}{ Head's education level $* * *$} \\
\hline No formal education & 2756 & 21.0 \\
\hline Primary & 1361 & 25.3 \\
\hline Secondary & 1861 & 27.6 \\
\hline Tertiary & 502 & 30.5 \\
\hline \multicolumn{3}{|l|}{ Head's occupation status $* * *$} \\
\hline Not working & 621 & 27.5 \\
\hline Working, informal sector & 4617 & 22.2 \\
\hline Working, formal sector & 1242 & 31.6 \\
\hline \multicolumn{3}{|l|}{ Head's caste/ethnicity $* * *$} \\
\hline Tharu & 3152 & 22.6 \\
\hline Brahmin/Chhetri & 1876 & 30.9 \\
\hline Other castes & 1452 & 25.1 \\
\hline \multicolumn{3}{|l|}{ Head's religion } \\
\hline Hinduism & 6110 & 24.5 \\
\hline Non-Hindu & 370 & 25.9 \\
\hline \multicolumn{3}{|l|}{ Enrollment in health insurance $* * *$} \\
\hline Enrolled & 1747 & 28.5 \\
\hline Not enrolled & 4733 & 23.1 \\
\hline \multicolumn{3}{|l|}{ Family size $* * *$} \\
\hline 4 or less & 1071 & 26.8 \\
\hline 5 to 8 & 3628 & 26.0 \\
\hline 9 or more & 1781 & 20.2 \\
\hline \multicolumn{3}{|l|}{ Household economic status/Wealth index** } \\
\hline $1^{\text {st }}$ quintile (Poorest) & 964 & 25.1 \\
\hline $2^{\text {nd }}$ quintile (Poorer) & 1145 & 26.1 \\
\hline $3^{\text {rd }}$ quintile (Middle) & 1328 & 21.4 \\
\hline $4^{\text {th }}$ quintile (Richer) & 1465 & 25.5 \\
\hline $5^{\text {th }}$ quintile (Richest) & 1578 & 24.8 \\
\hline Total of each variable & 6480 & 24.5 \\
\hline
\end{tabular}

$* * * p<0.01 . \quad * * p<0.05 . \quad * p<0.10 . p$-value is based on Pearson's $\chi^{2}$ statistic

Individuals were more likely to report illness among those whose head worked in the formal sector as compared to those whose head worked only in the informal sector ( $32 \%$ vs. $22 \%$ ). The illness reporting also varied according to occupation status of household heads. The proportions 
of individuals reporting illness was highest among those whose heads were employed in modern sectors. Individuals whose heads were employed in informal sectors (such as agricultural sector, unskilled laborer) were least likely to report illness. With regard to caste/ethnicity, Brahmin / Chhetri were more likely to report illness compared to other ethnic groups. Religion of household head did not show any significant association with regard to reporting illness of individual household member.

Individuals were more likely to report illness if their household got enrolled in the health insurance program compared to those whose household was not enrolled in the health insurance program. The percentage of reported illness was $29 \%$ among those who were insured, whereas it was only $23 \%$ among those who were not insured, and the difference is statistically significant $(\mathrm{p}<0.01)$. Individuals from smaller family size were more likely to report illness compared to larger family size. Significant differentials were also found according to the economic status of households. Individuals who were from the second quintile group were more likely to report illness compared to the individuals from other quintile groups. Comparatively, poorer groups were more likely to report illness than wealthier groups.

\subsection{Illness Reporting by Community Characteristics}

Table 4 shows the distribution of reported illness of individuals according to the health service accessibility factors. Though not significant, higher proportions of urban individuals than of rural individuals reported illness in the month prior to the survey.

The health service accessibility factor revealed significant variation with reporting illness of individuals. Particularly, 27\% of individuals reported illness among those whose distance to modern health care facilities was within half an hour, while it was only $21 \%$ if their distance to a health facility was more than half an hour. Similarly, accessibility in terms of access to motorable road also increases the likelihood of reporting illness. For example, 25\% of individuals who had access to motorable road within 30 minutes reported illness, while it was only $17 \%$ among those who had access to motorable road more than 30 minutes.

Table 4. Illness Reporting by Accessibility Factors in the Month Prior to the Survey

\begin{tabular}{ccc}
\hline Characteristics & Number & Percent \\
\hline Urban/rural status & & \\
Urban municipality & 4758 & 24.8 \\
Rural municipality & 1722 & 23.8 \\
Access to health facility $* * *$ & & \\
& & \\
\hline
\end{tabular}

11 Paudel 
Volume $3 \quad$ Issue $3 \quad$ Dec 2020

2565-4942 (Print) 2738-9693 (online)

\begin{tabular}{cll}
\hline Characteristics & Number & Percent \\
\hline Within half an hour & 4118 & 26.7 \\
More than half an hour & 2362 & 21.0 \\
Access to motorable road $* * *$ & & \\
Within half an hour & 6303 & 24.8 \\
More than half an hour & 177 & 16.9 \\
\hline Total of each variable & 6480 & 24.5 \\
\hline
\end{tabular}

${ }^{* * *} p<0.01 . \quad * * p<0.05 . \quad * p<0.10 . p$ - value is based on Pearson's $\chi^{2}$ statistic

\subsection{Results from Logistic Regression Analysis: What Determines Illness Reporting?}

In this section, the results of logistic regression analysis predicting the illness reporting of household members in the month prior to the survey are discussed. To control for the confounding influence of the socio-demographic and other factors, a model was fitted for the outcome variable to identify the independent associations between the socio-demographic indicators and illness reporting. The multicollinearity among the independent variables was assessed by using both correlation matrix and Variance Inflationary Factor (VIF). The correlation matrix showed that none of the explanatory variables were highly correlated. A rule of thumb indicating the multicollinearity is such that if the correlation between the independent variables is more than 0.70 , then there is reason to suspect the problem of multicollinearity (Marquardt, 1980). Furthermore, it was found that VIF was less than 5 for each of the independent variables (Table 5). According to Gujarati (2003), the VIF value greater than 5 indicates the problem of multicollinearity. Some other researchers suggest that if VIF is greater than 10, there is too much correlation among the independent variables (Marquardt, 1980). In this study, there were not any problems of multicollinearity; and thus, a full block of independent variables was included in the logistic regression model.

Table 5. VIF among the Independent Variables for Checking Multi-Collinearity

\begin{tabular}{ll}
\hline Explanatory variables & VIF \\
\hline Head working, formal sector & 4.25 \\
Head working, informal sector & 3.93 \\
Being married & 3.20 \\
Age in completed years & 3.12 \\
Being student & 2.53 \\
Working, informal sector & 2.29 \\
Head education in completed school years & 2.12 \\
Working, formal sector & 1.98 \\
Being widow or separated & 1.88
\end{tabular}

Nepalese Journal of Insurance and Social Security 12 
Vol. 3(3) Dec 2022 ISSN: 2565-4942 (Print) 2738-9693 (online)

\begin{tabular}{ll}
\hline Explanatory variables & VIF \\
\hline Being head & 1.69 \\
Being Brahmin/Chhetri & 1.66 \\
Education of individuals in completed school years & 1.65 \\
Head age in completed years & 1.48 \\
Being female head & 1.48 \\
Being other castes & 1.41 \\
Being female & 1.40 \\
Natural log of income per capita & 1.30 \\
Living in urban area & 1.23 \\
Family size & 1.23 \\
Access to health facility within half an hour & 1.20 \\
Access to motorable road within half an hour & 1.17 \\
Have health insurance & 1.15 \\
Have own dwelling & 1.06 \\
Being Hindu & 1.05 \\
\hline
\end{tabular}

Note. Age, Education, Head age, Head education, Family size, Natural log of income per capita were measured in interval scale and others are dummy variables: $1=$ Yes; $0=N o$

The results from Logistic regression analysis showing the adjusted odds ratios (AORs) of reporting illness in the month prior to the survey have been presented in Table 6. Only full model consisting of all potential confounders have been discussed since it has the highest predictability among other equivalent models. A number of individual, household, and accessibility characteristics emerged as significant predictors for reporting illness.

Individual characteristics such as gender revealed that females were $34 \%$ more likely to report illness as compared to males, after controlling other potential confounders (Odds ratio $=1.34$, 95\% CI=1.19-1.52). As expected, an individual's age was found to be significantly associated with reporting of illnesses and injuries. Children aged less than 4 years and senior citizens aged 60 years or above were more likely to report illness as compared to the individuals aged 5 to 59 years. It is known from earlier research that an individual's age influences the likelihood of illness. In developing countries, we would expect a U-shaped relationship between age and morbidity, implying that the health risks are highest for infants and elderly (Heller, 1982).

Table 6. Determinants of Reporting an Illness in the Month Prior to the Survey

\begin{tabular}{lllll}
\hline Explanatory/ & Categories/ & \multicolumn{2}{c}{ Odds } & \multicolumn{2}{c}{$95 \%$ CI } \\
Independent variables & Attributes & Ratio & Lower & Upper \\
\hline Gender (Male $=\mathrm{R})$ & Female & $1.34 * * *$ & 1.19 & 1.52 \\
Being head (Not head=R) & Head & $1.31 * * *$ & 1.09 & 1.57 \\
Age group in years $(5$ to $59=\mathrm{R})$ & 0 to 4 (Child) & $3.12 * * *$ & 2.43 & 4.03
\end{tabular}




\begin{tabular}{|c|c|c|c|c|}
\hline \multirow[t]{2}{*}{ Explanatory/ } & \multirow{2}{*}{$\begin{array}{l}\text { Categories/ } \\
60 \text { or more (Senior) }\end{array}$} & \multirow{2}{*}{$\begin{array}{l}\text { Odds } \\
2.46^{* * * *}\end{array}$} & \multicolumn{2}{|c|}{$95 \% \mathrm{CI}$} \\
\hline & & & 1.92 & 3.15 \\
\hline \multirow[t]{2}{*}{ Marital status (Unmarried =R) } & Married & $1.32 * * *$ & 1.11 & 1.57 \\
\hline & Widow or other & $1.40 *$ & 1.08 & 1.95 \\
\hline Head's gender $($ Male=R $)$ & Female & $1.22 *$ & 1.02 & 1.45 \\
\hline Head's age in completed years & & 0.99 & 0.99 & 1.00 \\
\hline \multirow[t]{2}{*}{ Head's caste/ethnicity (Tharu=R) } & Brahmin/Chhetri & 1.01 & 0.85 & 1.19 \\
\hline & Other castes & 0.86 & 0.71 & 1.04 \\
\hline Head's religion (Non-Hindu=R) & Hindu & 1.09 & 0.86 & 1.36 \\
\hline Family size & & $0.91 * * *$ & 0.89 & 0.93 \\
\hline \multirow[t]{3}{*}{ Education level (No education $=\mathrm{R}$ ) } & Primary & 0.82 & 0.65 & 1.05 \\
\hline & Secondary & $0.58 * * *$ & 0.46 & 0.74 \\
\hline & Tertiary & $0.49 * * *$ & 0.37 & 0.65 \\
\hline \multirow[t]{3}{*}{ Occupation status (Not working=R) } & Working, informal sector & $0.63 *$ & 0.53 & 0.74 \\
\hline & Student & 0.99 & 0.81 & 1.22 \\
\hline & Working, formal sector & $0.65 * * *$ & 0.52 & 0.81 \\
\hline \multirow[t]{3}{*}{ Head's education (No education $=\mathrm{R}$ ) } & Primary & $1.28 * *$ & 1.12 & 1.45 \\
\hline & Secondary & $1.17 *$ & 1.01 & 1.34 \\
\hline & Tertiary & $1.27 *$ & 1.02 & 1.59 \\
\hline \multirow[t]{2}{*}{ Head's occupation (Not working $=\mathrm{R}$ ) } & Working, informal sector & 1.25 & 0.99 & 1.58 \\
\hline & Working, formal sector & 1.16 & 0.88 & 1.53 \\
\hline Health insurance (Not enrolled =R) & Enrolled & $1.40 * * *$ & 1.24 & 1.59 \\
\hline \multirow[t]{4}{*}{ Household economic status (Poorest= R) } & Poorer & 0.87 & 0.72 & 1.05 \\
\hline & Middle & $0.69 * * *$ & 0.57 & 0.83 \\
\hline & Richer & $0.76 * * *$ & 0.63 & 0.91 \\
\hline & Richest & $0.60 * * *$ & 0.49 & 0.74 \\
\hline Rural urban (Rural municipality=R) & Urban municipality & $1.13 *$ & 1.02 & 1.26 \\
\hline $\begin{array}{l}\text { Access to health facility } \\
\text { (More than half an hour }=\mathrm{R} \text { ) }\end{array}$ & Within half an hour & $1.22 * * *$ & 1.09 & 1.38 \\
\hline $\begin{array}{l}\text { Access to motorable road } \\
\text { (More than half an hour =R) }\end{array}$ & Within half an hour & $1.34 * * *$ & 1.02 & 1.81 \\
\hline Total number of household members & & 6480 & & \\
\hline
\end{tabular}

$* * * p<0.001, * * p<0.01, * p<0.05, R=$ Reference category, Model correctly classified $=65.5 \%$,

Pseudo $R^{2}=0.0896, L R\left(\chi^{2}\right)=802.79$, Model sig. $p$ value $<0.001$, Unit of analysis $=$ Household members .

An individual's education was only significant for secondary and tertiary levels. Individuals with secondary level of education were $42 \%$ less likely to have illnesses than individuals with no formal education (Odds ratio= 0.58). Similarly, individuals with tertiary level of education were $51 \%$ less likely to have illnesses than the individuals with no education (Odds ratio $=0.49$ ). Married and widowed people were significantly more likely to have illness compared to their unmarried counterparts. Being employed or occupied either in formal or informal sector, individuals were less likely to have illness compared to the individuals who were not working. 
Concerning to household characteristics, a number of key indicators, such as head's gender, head's education, health insurance coverage, family size, economic status, had effect on reporting illness. The odds of illness reporting were $22 \%$ higher in female-headed households than male-headed households. Being insured, individuals were more likely to report illness, whereas individuals from larger family size were less likely to report illness. The study found that individuals from higher household economic status were significantly less likely to have an illness.

Individuals in urban households were more likely to report an illness than their rural counterparts after controlling for other factors. Individuals who had access to modern health facilities and motorable road within half an hour of distance were more likely to report an illness than individuals who lived in a community far more than half an hour.

\section{DISCUSSION}

Illness is a health shock but it is perceived differently by households according to various socioeconomic status. For instance, less educated and poorer households are less likely to report simple illnesses. So, the level of awareness could be the significant predictor of illness reporting. This survey relied upon respondents' self-assessment of illness indicating the methodological constraints in interview-based health surveys (Ross \& Vaughan, 1986). The reliance on selfrecall may be somehow problematic. Respondents could not always recall the illness and there could be the possibility of reporting biases (Ross \& Vaughan, 1986). Thus, the findings presented here should be treated with caution. This study aimed at identifying households with an illness where the social health insurance program was first piloted in Nepal.

To collect information on illness/injury, respondents were asked to report all household members affected by illness or injury in the month prior to the survey, by interviewing mainly the household heads or spouses. There are methodological limitations or constraints regarding reporting of illnesses. The widely used limitations mentioned in the literature are recalled and selection biases, commonly found in interview-based health surveys (Fabricant \& Harpham, 1993; Ir et al., 2010; Ross \&Vaughan, 1986). For example, talking about possible recall bias, the respondent may indeed not accurately remember the illness history of all household members. In

15 Paudel 
this study, the recall bias was minimized because the study focused on illness that occurred within a short period of time, which was only one month prior to the survey. Also, the data collection was carried out by a group of experienced and well-trained field enumerators or by the principal investigator. Selection bias may also be limited given the relatively big sample size. Furthermore, the sex, age, ethnic, religious, family size, and urban-rural structure of this survey population was also more or less similar to that of the studied district population. The probability of reporting a perceived illness does not only depend on its incidence or prevalence in the survey population, but also on the respondent's awareness and perceptions and several such studies of illness were based on reported or perceived illness (McIntyre et al., 2006; Russell, 2004). This suggests that despite some methodological limitations in reported illness, careful analysis and interpretation of the findings could still yield useful information for further understanding of the self-reported illness.

The main purpose of this study was to estimate the level of illness reporting and factors associated with it. The findings show that out of 6480 surveyed individuals, nearly one in four (1590 individuals or 24.5\%) reported illness in the month prior to the survey. The most commonly self-reported illness in the month prior to the survey was cold/cough/fever followed by gastritis/abdominal pain.

The hypothesis testing from the logistic regression model showed education as a significant predictor of illness reporting following a post-positivism research paradigm, a deductive method of quantitative inquiry. This result is consistent with Grossman's theory indicating that better educated persons are, through healthier lifestyles, expected to be more efficient producers of health (Grossman, 1972). Being females, they were more likely to report illness after controlling for socio-demographic and other potential confounders. This result is parallel to the previous studies conducted in Nepal and Georgia indicating the widespread assumption that women experience considerably more ill-health than men (Rous \& Hotchkiss, 2003; Gotsadze et al., 2005). Rodgers (2009) also pointed out that women were more likely to be sick than men in Cambodia. Furthermore, many health indicators exhibit considerable gender differences according to an individual's social position and role (Berhane et. al, 2002). A possible explanation for this high frequency of reported illness among women could be that women in this sample were proportionally older than men while the prevalence of diseases correlates with age. Out of 527 enumerated household members aged 60 or more years in the study sample, $52 \%$ 
were females and $48 \%$ were males. Children aged less than 5 years or senior citizens aged 60 years or above were more likely to have illness. This implies that the health risks are higher for infants and the elderly as found in the earlier research (Heller, 1982).

Concerning household characteristics, a number of key indicators, such as gender of household head, household health insurance enrolment status, family size, economic status have effect on illness reporting. Individuals in households headed by females were more likely to report illness than individuals in households headed by males. The study found that individuals from higher household economic status were significantly less likely to have an illness. This result is in line with the findings of Sen (1999), which states that richer people have fewer illnesses and live longer. This could be the reason that with a higher wealth status and thereby a higher budget, the individuals can increase their investment in health (Grossman, 1972). The significant poor-rich difference could be due to the higher risk of illness and vulnerability to health shocks among the poor, as poor people often have worse health and suffer more often from severe health problems than the rich do (Gwatkin et al., 2007). Individuals from poor household economic status were more likely to have illness. The poor-rich difference could be due to the higher risk of illness and vulnerability to health shocks among the poor, as poor people often have worse health conditions and suffer more often from severe health problems than the rich do (Gwatkin et al., 2007). Individuals who had access to modern health facility and motorable road within half an hour of distance were more likely to report an illness than individuals who lived in a community farther than half an hour.

\section{Limitations of the Study}

The study has some limitations that need to be acknowledged. First, this is a cross-sectional survey conducted in one district of Nepal. The cross-sectional nature of the data only provides the estimates of illness reporting at one point of time. Thus, long-term perfect causal associations cannot be perfectly inferred from this study. Second, collecting data on the illness reporting can be very costly and time-consuming and self-reported illness from the survey may be prone to recall/reporting bias. However, self-reported illness surveys have been widely used for decades

in a variety of academic disciplines (Bhandari, 2006). Third, it would have been useful to consider supply-side factors. However, information on supply factors was lacking in this study. This could be a key area for further research and a qualitative approach is suggested to capture 
supply-side factors. Thus, this study captures only potential predicting factors of individual, household, and community characteristics. Fourth, variations in the seasonality of diseases in the study district were not considered. For example, the study was conducted between November 2017 and January 2018 - i.e. in the winter season. The timing of the survey may well have affected the self-reported illness such as colds, which tend to be more usual in winter than in summer. However, as per the latest national survey of Nepal, cold/cough/fever was the most predominant reported illness throughout the year (CBS, 2011).

\section{CONCLUSION AND POLICY IMPLICATIONS}

The results of this study have important policy implications. The findings from this study could inform policy in the ongoing national health insurance debate in Nepal and elsewhere. Since household members having health insurance are more likely to report illness compared to uninsured suggests that there is need to expand the health insurance program thought the country. Despite some methodological constraints, this study provides new information on the occurrences of self-reported illnesses among the Nepalese population, which could serve the basis for further in-depth investigation on illness reporting and economic consequences especially for poor households. This can in turn help policy makers to formulate proper interventions to protect the poor from the financial burden associated with ill-health. Furthermore, in order to minimize the economic burden of illness, several approaches need to be adopted, including social health insurance complemented with an upgraded community-based health insurance system, and subsidy program expansion for illness/diseases with high economic burden.

\section{ACKNOWLEDGMENTS}

The author would like to acknowledge University Grants Commission (UGC) Nepal for providing the financial support to conduct this study under Ph.D. fellowship in 2017. Further, the author would like to extend sincere thanks to NHRC and PURC for ethical clearances; KUSOED for providing an opportunity for conducting the Ph.D. study; SHSDC for data collection approval, and respondents for their participation. 
Vol. 3(3) Dec 2022 ISSN: 2565-4942 (Print) 2738-9693 (online)

\section{References}

Beogo, I., Huang, N. Gagnon, M.P., \& Djesika D. Amendah, D.D. (2016). Out-of-pocket expenditure and its determinants in the context of private healthcare sector expansion in sub-Saharan Africa urban cities: Evidence from household survey in Ouagadougou, Burkina Faso. BMC Research Notes, 9, 34. https://doi.org/10.1186/s13104-016-1846-4

Berhane, Y., Hogberg, U., Byass, P., \& Wall, S. (2002). Gender, literacy, and survival among Ethiopian adults, 1987-96. Bulletin of the World Health Organization,80(9), 714-720. https://www.scielosp.org/article/bwho/2002.v80n9/714-720/en/

Bhandari, A. (2006). Self-reported utilization of health care services: Improving measurement and accuracy. Medical Care Research and Review, 63(2), 217-235. https://doi.org/10.1177/1077558705285298

Central Bureau of Statistics /The World Bank. (2013). Nepal small area estimation of poverty 2011. Kathmandu: Author. https://cbs.gov.np/nepal-small-area-estimates-of-poverty$\underline{\text { 2011-data-viz/ }}$

Central Bureau of Statistics. (2011). Nepal living standards survey 2011. Kathmandu: Author. https://cbs.gov.np/nepal-living-standard-survey-2010-11

Central Bureau of Statistics. (2012). National population and housing census 2011(National Report). https://cbs.gov.np/national-population-and-housing-census-2011national-report/

Deaton, A., \& Zaidi, S. (2002). Guidelines for constructing consumption aggregates for welfare analysis. Living standards measurement study [Working paper no. 135]. Washington DC: World Bank.

Fabricant, S.J., \& Harpham, T. (1993). Assessing response reliability of health interview surveys using reinterviews. Bulletin of World Health Organization, 71, 341-348. https://www. ncbi.nlm.nih.gov/pmc/articles/PMC2393501/

Gotsadze, G., Bennett, S., Ranson, K., \& Gzirishvili, D. (2005). Health care-seeking behavior and out-of-pocket payments in Tbilisi, Georgia. Oxford University Press \& London School of Hygiene and Tropical Medicine. https://doi.org/10.1093/heapol/czi029 
Volume 3 Issue $3 \quad$ Dec 2020 2565-4942 (Print) 2738-9693 (online)

Grossman, M. (1972). On the concept of health capital and the demand for health. The Journal of Political Economy, 80, 223-255. https://www.journals.uchicago.edu/doi/pdf/10. $\underline{1086 / 259880}$

Gwatkin, D. R., Rutstein, S., Johnson, K., Suliman, E., Wagstaff, A., \& Amouzou, A. (2007). Socio-economic differences in health, nutrition, and population within developing countries. Washington DC: World Bank. https://commed.vcu.edu/IntroPH/Underserved /2008/IndicatorsOvervieWorldBank.pdf

Heller, P.S. (1982). A model of the demand for medical and health services in Peninsular Malaysia. Social Science \& Medicine, 16(3), 267-284. https://doi.org/10.1016/0277$\underline{9536(82) 90337-9}$

Ir, P., Men, C., Lucas, H., Meessen, B., Decoster, K., Bloom, G., \& Van Damme, W. (2010). Self-reported serious illnesses in rural Cambodia: a cross-sectional survey. PloS one, 5(6), 1-12. https://doi.org/10.1371/journal.pone.0010930

KOICA-Nepal Health Insurance Support Project. (2014). Comprehensive district assessment for health insurance in Kailali district. Lalitpur, Nepal: Author.

Marquardt, D.W. (1980). You should standardize the predictor variables in regression models discussion of: A critique of some ridge Regression methods by G. Smith and F. Campell. Journal of the American Statistical Association, 75, 87-91. https://doi.org/10.1080/01621459.1980.10477430

Masiye, F., \& Kaonga, O. (2016). Determinants of health care utilization and out-of-pocket payments in the context of free public primary healthcare in Zambia. International Journal of Health Policy and Management, 5(12), 693-703. https://doi.org/ 10.15171/ijhpm.2016.65

McIntyre, D., Thiede, M., Dahlgren, G., \& Whitehead, M. (2006). What are the economic consequences for households of illness and of paying for health care in low-and middleincome country contexts? Social Science \& Medicine, 62(4), 858-865. https://doi.org $\underline{\text { /10.1016/j.socscimed.2005.07.001 }}$

Nepalese Journal of Insurance and Social Security 20 
Vol. 3(3) Dec 2022 ISSN: 2565-4942 (Print) 2738-9693 (online)

Ministry of Health and Population. (2018). Nepal national health accounts 2012/13-2015/16. Kathmandu: MoHP. http://www.searo.who. int/nepal/documents /nepal_nha_2012_ 13_2015_16_mohp_june_2018.pdf

Pokharel, R., \& Silwal, P. R. (2018). Social health insurance in Nepal: A health system departure toward the universal health coverage. International Journal of Health Planning and Management, 33(3), 573-580. https://doi.org/10.1002/hpm.2530

Rodgers, Y. M. (2009). The health status of Cambodia's elderly in a context of gendered violence. Gender \& Development,17(3), 453-465. https://doi.org/10.1080/135520 $\underline{70903298469}$

Ross, D. A., \& Vaughan, J. P. (1986). Health interview surveys in developing countries: a methodological review. Studies in Family Planning, 17(2), 78-94. https://doi.org/ $\underline{10.2307 / 1967068}$

Ross, K.N. (2005). Sample design for educational survey research: Quantitative research methods for educational planning. Paris, France: UNESCO International Institute for Educational Planning. http://www.sacmeq.org and http://www.unesco.org/iiep.

Rous, J. J., \& Hotchkiss, D. R. (2003). Estimation of the determinants of household health care expenditures in Nepal with controls for endogenous illness and provider choice. Health Economics, 12(6), 431-451. https://doi.org/10.1002/hec.727

Russell, S. (2004). The economic burden of illness for households in developing countries: A review of studies focusing on malaria, tuberculosis, and human immunodeficiency virus/acquired immunodeficiency syndrome. The American Journal of Tropical Medicine and Hygiene, 71(2_suppl), 147-155. https://doi.org/10.4269/ajtmh.2004.71.147

Saito, E., Gilmour, S., Rahman, M. M., Gautam, G. S., Shrestha, P. K., \& Shibuya, K. (2014). Catastrophic household expenditure on health in Nepal: A cross-sectional survey. Bulletin of the World Health Organization, 92(10), 760-767. https://doi.org/ $\underline{10.2471 / B L T .13 .126615}$

Sen, A. (1999). Economics and health. The Lancet, 354, (SIV20). https://doi.org/10.1016/s01406736(99)90363-х

21 Paudel 
Volume 3 Issue $3 \quad$ Dec 2020 2565-4942 (Print) 2738-9693 (online)

Shackman, G. (2001). Sample size and design effect. Albany Chapter of American Statistical Association. NYS DOH. http://faculty.smu.edu/slstokes/stat6380/deff doc.pdf StataCorp. (2012). Intercooled statistical software 12 for windows. College Station TX: StataCorporation.

United Nations. (2008). Designing household survey samples: Practical guidelines. (No. 98). New York: Department for Economic and Social Affairs. https://unstats.un.org /unsd/demographic/sources/surveys/Series_F98en.pdf

Wagstaff, A. (2002). Poverty and health sector inequalities. Bulletin of the World Health Organization, 80, 97-105. https://www.scielosp.org/article/bwho/2002.v80n2/97-105/en/

Wang, H., Zhang, L., \& Hsiao, W. (2006). Ill health and its potential influence on household consumptions in rural China. Health Policy, 78(2-3), 167-177. https://doi.org/ 10.1016/ j.healthpol.2005.09.008

Wang, S. Y., Chen, L. K., Hsu, S. H., \& Wang, S. C. (2012). Health care utilization and health outcomes: A population study of Taiwan. Health Policy and Planning, 27(7), 590-599. https://doi.org/10.1093/heapol/czr080

World Bank. (2017). What can we learn from the Nepal social health security program implementation process? Kathmandu, Nepal (World Bank Country Office): World Bank Group Health Nutrition \& Population

Xu, K., Evans, D. B., Kawabata, K., Zeramdini, R., Klavus, J., \& Murray, C. J. (2003). Household catastrophic health expenditure: a multicountry analysis. The Lancet, 362(9378), 111-117. https://doi.org/10.1016/S0140-6736(03)13861-5

Nepalese Journal of Insurance and Social Security 22 